\title{
Aspartate aminotransferase - risk marker for type-2 diabetes mellitus or red herring?
}

\author{
Setor K. Kunutsor ${ }^{1}$, Ali Abbasi ${ }^{2,3,4}$ and Tanefa A. Apekey ${ }^{5}$ \\ ${ }^{5}$ Sport, Health and Nutrition Department, Leeds Trinity University, Leeds, UK \\ *Correspondence: skk31@cantab.net \\ Edited by: \\ Soroku Yagihashi, Hirosaki University Graduate School of Medicine, Japan \\ Reviewed by: \\ Hideyuki Sasaki, Wakayama Medical University, Japan \\ Toru Aizawa, Aizawa Hospital, Japan \\ Zhong Q. Wang, Pennington Biomedical Research Center, USA
}

${ }^{1}$ Cardiovascular Epidemiology Unit, Department of Public Health and Primary Care, University of Cambridge, Cambridge, UK

${ }^{2}$ MRC Epidemiology Unit, Institute of Metabolic Science, Cambridge Biomedical Campus, University of Cambridge School of Clinical Medicine, Cambridge, UK

${ }^{3}$ Department of Epidemiology, University Medical Center Groningen, University of Groningen, Groningen, Netherlands

${ }^{4}$ Department of Internal Medicine, University Medical Center Groningen, University of Groningen, Groningen, Netherlands

Keywords: aspartate aminotransferase, type-2 diabetes mellitus, liver enzymes, risk factors, meta-analysis

\section{INTRODUCTION}

Gamma glutamyltransferase (GGT), alanine aminotransferase (ALT), aspartate aminotransferase (AST), and alkaline phosphatase (ALP) are common liver enzymes. Abnormal serum circulating levels of these enzymes may signal liver or cholestatic damage (1). Circulating GGT is present on the external surfaces of most cells, particularly hepatocytes, and is used as a biological marker of excessive alcohol intake (2). ALT and AST catalyze the transfer of amino groups to generate products in gluconeogenesis and amino acid metabolism $(3,4)$. Elevated serum levels of these aminotransferases signal acute or chronic liver injury (1). ALP is a hydrolase enzyme that transports metabolites across cell membranes, with elevated serum levels commonly used in clinical practice as a marker of liver or bony disease $(1,5)$.

In addition to their physiological functions, a growing body of evidence indicates that baseline serum levels of these enzymes may be associated with the development of a wide range of disease outcomes. Several reports have indicated that among these enzymes, elevated baseline levels of GGT and ALT are each associated with increased risk of future type-2 diabetes mellitus (T2DM) $(6,7)$. Indeed, the associations are apparent even within normal ranges of these enzymes. There is, however, considerable uncertainty regarding the association between AST level and risk of T2DM. In a recent review, we synthesized available prospective epidemiological data on the association between AST and incident T2DM (7). The pooled analyses involving 1,912 incident T2DM cases did not show a significant association between AST and risk of future T2DM. In contrast, a recently rigorously conducted prospective study involving 2,182 incident T2DM cases, reported a multivariate adjusted relative risk (RR) of 1.16 (1.02-1.31) for T2DM in a comparison of the highest to the lowest quartile of baseline AST levels (8). The association was continuous and extended well within the normal range of AST levels. This large study adds to the growing body of evidence that like GGT and ALT, elevated AST level may also be associated with increased risk for T2DM.

The prospective evidence on the association between AST and T2DM is inconclusive and this may be attributed to several reasons including: lack of adequate power, unmeasured confounding, or even over-adjustment for potential intermediates by previous studies. Given that levels of serum liver enzymes (GGT, ALT, and AST) (i) are strongly environmentally and genetically correlated with one another (9), and (ii) have shared genetic variances (10), the evidence is suggestive of common biological pathways affecting levels of these enzymes. There is therefore a possibility that the association between AST level and risk of T2DM might be mediated through the effects of the other liver enzymes. The potential impact of other liver enzymes on the AST-T2DM association is unclear as it is uncertain whether adjusting for such putative intermediates is appropriate. There are indications that further adjustment for other liver enzymes may be responsible for the substantially attenuated or null associations observed in several studies. To help clarify the evidence, we report an updated review.

\section{METHODS}

We searched MEDLINE, EMBASE, and Web of Science electronic databases for published studies reporting on the associations between baseline AST levels and incident T2DM since the date of the previous review (7). Details of the review methodology and inclusion/exclusion criteria have been reported previously (7). Briefly, studies were only included if they had at least 1 year of follow-up, recruited participants from approximately general populations (i.e., did not select participants on the basis of pre-existing diabetes or known liver disease), and excluded participants with marked elevations in AST levels. Data were abstracted on several study characteristics including degree of adjustment for potential confounders (defined as " + " when RRs were adjusted for age and/or sex; " ++ " further adjustment for established diabetes risk factors; and " +++ " additional adjustment for liver enzymes). We separately extracted estimates from models adjusting for established and potential diabetes risk factors and models with additional adjustment for other liver enzymes. We contacted authors of eligible studies where the published data were insufficient, 


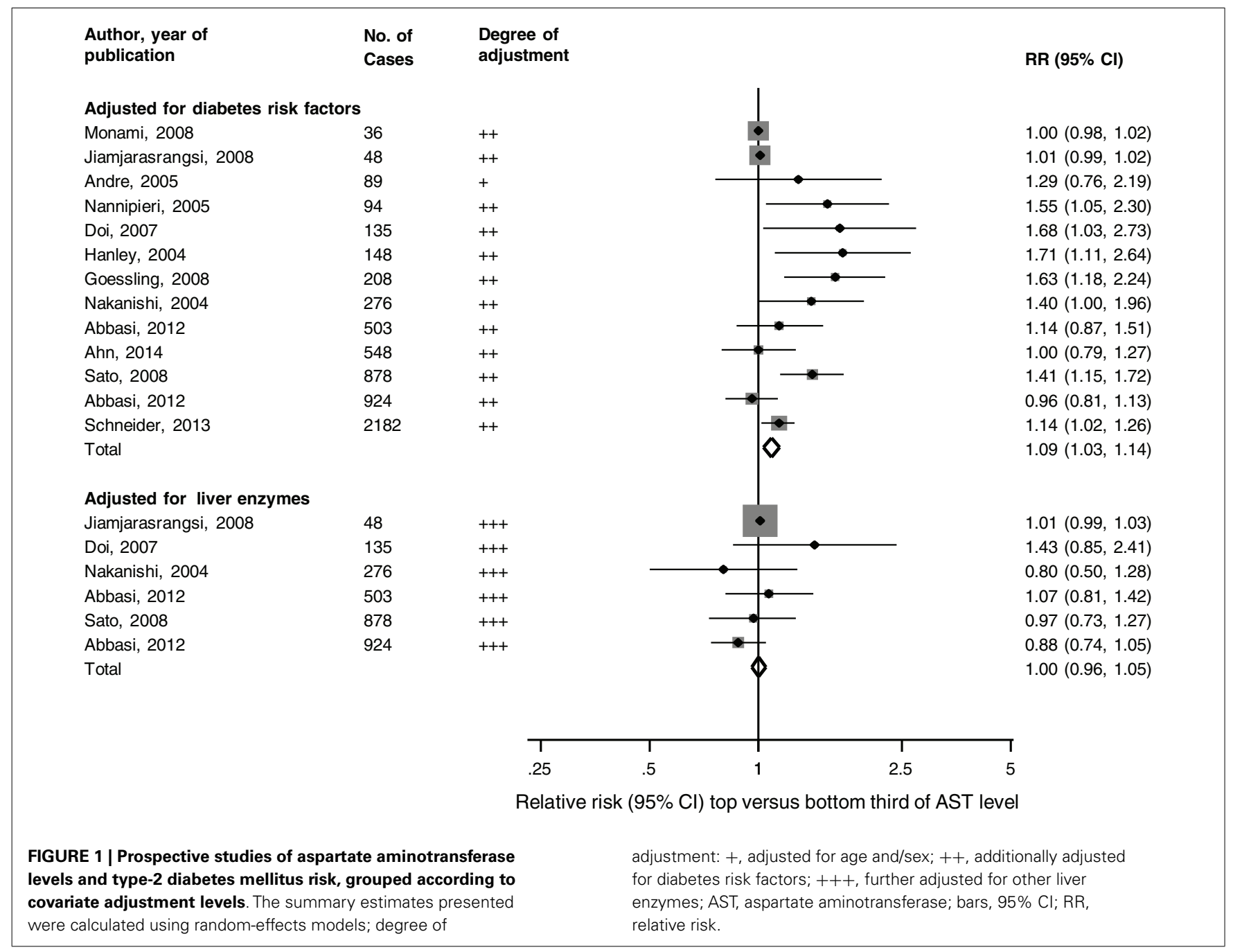

to provide relevant missing information. Risk estimates were transformed to involve comparisons between the top third and bottom third of the study population's baseline distribution of AST levels. Consistency of findings across studies was assessed by standard $\chi^{2}$ and $I^{2}$ statistics (11). Prespecified sources of potential heterogeneity were explored by using random-effects meta-regression. Evidence of publication bias was assessed using Begg's funnel plots and Egger's asymmetry test $(12,13)$. All analyses were performed using Stata release 12 (StataCorp, College Station, TX, USA).

\section{RESULTS}

Data were available on 90,975 participants from 13 unique prospective cohort studies (14-24) (of which, 9 were included in the previous review) (Table S1 in Supplementary Material). The cumulative analysis involved 6,069 incident T2DM cases, collected over average follow-up periods ranging from 3 to 20 years. The pooled randomeffects RR (95\% CI) for T2DM in a comparison of extreme thirds of AST level was 1.09 (1.03-1.14) in studies that adjusted for potential diabetes risk factors. The corresponding RR was 1.00 (0.96-1.05) in studies that additionally adjusted for other liver enzymes ( $P$ for meta-regression $=0.05$; Figure 1). There was substantial heterogeneity among the studies that adjusted for diabetes risk factors $\left(I^{2}=73 \%\right.$ : 54 $85 \%, P<0.001)$. The inconsistency was to a large part explained by duration of follow-up ( $P$ for meta-regression $=0.004$ ), with combined estimates from studies with follow-up duration $\geq 5$ years $(1.28,95 \% \mathrm{CI}$ : 1.11-1.49) being stronger than those with shorter follow-up duration $(1.02,95 \% \mathrm{CI}$ : 0.98-1.05). Egger's test was not significant
$(P=0.92)$, consistent with observed funnel plot symmetry.

\section{DISCUSSION}

The pattern of findings from the available evidence suggest that elevated AST is associated with increased risk of T2DM after controlling for potential confounding. Stronger associations were demonstrated for studies with longer duration of followup, findings, which confirm the speculative suggestion that duration of follow-up plays a role in the association between liver aminotransferases and T2DM (7). This finding may, however, require replication in further studies. The association of AST with T2DM was, however, abrogated by further adjustment for other liver enzymes. These results must be interpreted with caution given potential limitations such as effects of residual confounding, variably 
adjusted data, and the possibility for bias when attempting to assess the impact of putative intermediates (25) such as other liver enzymes (GGT and ALT). If other liver enzymes mediate the association, then correction for these enzymes may be an overadjustment by the studies concerned. The relationship between these liver enzymes and T2DM may be more complex than generally appreciated. Future studies are warranted to help provide insight into the nature of these processes and determine the joint role of these liver enzymes in the pathophysiology of T2DM.

\section{ACKNOWLEDGMENTS}

We thank the following authors for providing additional data on request: Dr. Soo Lim, Division of Endocrinology and Metabolism, Seoul National University College of Medicine; Dr. Wiroj Jiamjarasrangsi, Department of Preventive and Social Medicine, Faculty of Medicine, Chulalongkorn University; and Dr. Kyoko Kogawa Sato, Preventive Medicine and Environmental Health, Osaka City University Graduate School of Medicine. This work was supported by the Netherlands Organization for Scientific Research project (NWO) and the Medical Research Council UK (grant reference no. MC_U106179471). Ali Abbasi is supported by a Rubicon grant from the Netherlands Organization for Scientific Research (NWO). The NWO and MRC had no role in study design; in data collection, analysis, or interpretation; in writing the report; or in the decision to submit for publication.

\section{SUPPLEMENTARY MATERIAL}

The Supplementary Material for this article can be found online at http: //www.frontiersin.org/Journal/10.3389/

fendo.2014.00189/full

\section{REFERENCES}

1. Giannini EG, Testa R, Savarino V. Liver enzyme alteration: a guide for clinicians. CMAJ (2005) 172:367-79. doi:10.1503/cmaj.1040752

2. Whitfield JB. Gamma glutamyl transferase. Crit Rev Clin Lab Sci (2001) 38:263-355. doi:10.1080/ 20014091084227

3. Wroblewski F, Ladue JS. Serum glutamic pyruvic transaminase in cardiac with hepatic disease. Proc Soc Exp Biol Med (1956) 91:569-71. doi:10.3181/ 00379727-91-22330

4. Wroblewski F, Ladue JS. Serum glutamic oxalacetic aminopherase (transaminase) in hepatitis. $J \mathrm{Am}$
Med Assoc (1956) 160:1130-4. doi:10.1001/jama. 1956.02960480030008a

5. Tonelli M, Curhan G, Pfeffer M, Sacks F, Thadhani R, Melamed ML, et al. Relation between alkaline phosphatase, serum phosphate, and all-cause or cardiovascular mortality. Circulation (2009) 120:1784-92. doi:10.1161/CIRCULATIONAHA. 109.851873

6. Fraser A, Harris R, Sattar N, Ebrahim S, Davey SmithG, Lawlor DA. Alanine aminotransferase, gamma-glutamyltransferase, and incident diabetes: the British women's heart and health study and meta-analysis. Diabetes Care (2009) 32:741-50. doi:10.2337/dc08-1870

7. Kunutsor SK, Apekey TA, Walley J. Liver aminotransferases and risk of incident type 2 diabetes: a systematic review and meta-analysis. Am J Epidemiol (2013) 178:159-71. doi:10.1093/aje/ kws469

8. Schneider AL, Lazo M, Ndumele CE, Pankow JS, Coresh J, Clark JM, et al. Liver enzymes, race, gender and diabetes risk: the atherosclerosis risk in communities (ARIC) study. Diabet Med (2013) 30:926-33. doi:10.1111/dme.12187

9. Whitfield JB, Zhu G, Nestler JE, Heath AC, Martin NG. Genetic covariation between serum gammaglutamyltransferase activity and cardiovascular risk factors. Clin Chem (2002) 48:1426-31.

10. Rahmioglu N, Andrew T, Cherkas L, Surdulescu G, Swaminathan R, Spector T, et al. Epidemiology and genetic epidemiology of the liver function test proteins. PLoS One (2009) 4:e4435. doi:10.1371/ journal.pone.0004435

11. Higgins JP, Thompson SG. Quantifying heterogeneity in a meta-analysis. Stat Med (2002) 21:1539-58. doi:10.1002/sim.1186

12. Begg CB, Mazumdar M. Operating characteristics of a rank correlation test for publication bias. Biometrics (1994) 50:1088-101. doi:10.2307/2533446

13. Egger M, Davey Smith G, Schneider M, Minder C. Bias in meta-analysis detected by a simple, graphical test. BMJ (1997) 315:629-34. doi:10.1136/bmj. 315.7109.629

14. André P, Balkau B, Born C, Royer B, Wilpart E, Charles MA, et al. Hepatic markers and development of type 2 diabetes in middle aged men and women: a three-year follow-up study. The D.E.S.I.R. study (data from an epidemiological study on the insulin resistance syndrome). Diabetes Metab (2005) 31:542-50. doi:10.1016/S12623636(07)70229-X

15. Abbasi A, Bakker SJ, Corpeleijn E, van derADL, Gansevoort RT, Gans RO, et al. Liver function tests and risk prediction of incident type 2 diabetes: evaluation in two independent cohorts. PLoS One (2012) 7:e51496. doi:10.1371/journal.pone. 0051496

16. Goessling W, Massaro JM, Vasan RS, D’Agostino RB Sr, Ellison RC, Fox CS. Aminotransferase levels and 20-year risk of metabolic syndrome, diabetes, and cardiovascular disease. Gastroenterology (2008) 135(1935-44):44e1. doi:10.1053/j.gastro. 2008.09.018

17. Monami M, Bardini G, Lamanna C, Pala L, Cresci B, Francesconi P, et al. Liver enzymes and risk of diabetes and cardiovascular disease: results of the firenze bagno a ripoli (FIBAR) study. Metabolism
(2008) 57:387-92. doi:10.1016/j.metabol.2007.10. 015

18. Doi Y, Kubo M, Yonemoto K, Ninomiya T, Iwase $\mathrm{M}$, Tanizaki $\mathrm{Y}$, et al. Liver enzymes as a predictor for incident diabetes in a Japanese population: the Hisayama study. Obesity (Silver Spring) (2007) 15:1841-50. doi:10.1038/oby.2007.218

19. Hanley AJ, Williams K, Festa A, Wagenknecht LE, D'Agostino RB Jr, Kempf J, et al. Elevations in markers of liver injury and risk of type 2 diabetes: the insulin resistance atherosclerosis study. Diabetes (2004) 53:2623-32. doi:10.2337/diabetes.53. 10.2623

20. Sato KK, Hayashi T, Nakamura Y, Harita N, Yoneda T, Endo G, et al. Liver enzymes compared with alcohol consumption in predicting the risk of type 2 diabetes: the Kansai healthcare study. Diabetes Care (2008) 31:1230-6. doi:10.2337/dc07-2184

21. Nannipieri M, Gonzales C, Baldi S, Posadas R, Williams K, Haffner SM, et al. Liver enzymes, the metabolic syndrome, and incident diabetes: the Mexico city diabetes study. Diabetes Care (2005) 28:1757-62. doi:10.2337/diacare.28.7.1757

22. Nakanishi N, Suzuki K, Tatara K. Serum gammaglutamyltransferase and risk of metabolic syndrome and type 2 diabetes in middle-aged Japanese men. Diabetes Care (2004) 27:1427-32. doi:10. 2337/diacare.27.6.1427

23. Jiamjarasrangsi W, Sangwatanaroj S, Lohsoonthorn V, Lertmaharit S. Increased alanine aminotransferase level and future risk of type 2 diabetes and impaired fasting glucose among the employees in a university hospital in Thailand. Diabetes Metab (2008) 34:283-9. doi:10.1016/j.diabet.2008.01.009

24. Ahn HR, Shin MH, Nam HS, Park KS, Lee YH, Jeong SK, et al. The association between liver enzymes and risk of type 2 diabetes: the Namwon study. Diabetol Metab Syndr (2014) 6:14. doi:10.1186/1758-5996-6-14

25. Robins JM, Greenland S. Identifiability and exchangeability for direct and indirect effects. Epidemiology (1992) 3:143-55. doi:10.1097/00001648-199203000-00013

Conflict of Interest Statement: The authors declare that the research was conducted in the absence of any commercial or financial relationships that could be construed as a potential conflict of interest.

Received: 27 August 2014; accepted: 17 October 2014; published online: 04 November 2014.

Citation: Kunutsor SK, Abbasi A and Apekey TA (2014) Aspartate aminotransferase - risk marker for type-2 diabetes mellitus or red herring? Front. Endocrinol. 5:189. doi: 10.3389/fendo.2014.00189

This article was submitted to Diabetes, a section of the journal Frontiers in Endocrinology.

Copyright (C) 2014 Kunutsor, Abbasi and Apekey. This is an open-access article distributed under the terms of the Creative Commons Attribution License (CC BY). The use, distribution or reproduction in other forums is permitted, provided the original author(s) or licensor are credited and that the original publication in this journal is cited, in accordance with accepted academic practice. No use, distribution or reproduction is permitted which does not comply with these terms. 